\title{
LAS REPERCUSIONES DE LA APERTURA ECONÓMICA DE CUBA CON ESTADOS UNIDOS EN EL CONTEXTO DE LAS RELACIONES INTERNACIONALES
}

\author{
THE REPERCUSSIONS OF CUBA'S ECONOMIC \\ OPENING WITH THE UNITED STATES WITHIN THE \\ INTERNATIONAL RELATIONS CONTEXT
}

Juan Francisco Agramón-Mata ${ }^{1}$

ORCID: 0000-0002-6213-8203

\section{Jorge Isaac Lechuga-Cardozo ${ }^{2}$ \\ ORCID: 0000-0002-0999-5468}

\section{María del Pilar Arjona-Granados ${ }^{3}$ \\ ORCID: 0000-0003-1745-6023}

\section{RESUMEN}

El presente artículo tiene como objetivo mostrar evidencia de las repercusiones de la apertura económica de Cuba con Estados Unidos en el ámbito de las relaciones internacionales. Se aplicó el método de análisis con un enfoque cualitativo y un diseño no experimental a partir de una revisión documental-bibliográfica transversal. Tras la revisión documental se encontró que existe una ruptura diplomática y comercial entre Cuba y Estados Unidos que incide en la dinámica de las relaciones internacionales a nivel interamericano. Se concluye que, a pesar del acuerdo en 2014 entre Washington y La Habana, el gobierno de Trump mantuvo una serie de actos de hostilidad que inciden negativamente en el acuerdo pactado, por tanto, se deben buscar espacios de cooperación que mejoren los vínculos bilaterales.

Palabras clave: apertura económica, Cuba, diplomacia, Estados Unidos, cooperación internacional, relaciones interestatales

\section{ABSTRACT}

This article is a bibliographic review aiming to show evidence of the repercussions of Cuba's economic opening with the United States from the International Relations perspective. A qualitative approach was applied in which the analytical method was used through a documentary-bibliographic cross-sectional review. The research identifies a rupture in diplomatic and trade relations between Cuba and the United

1 Universidad Autónoma de Nuevo León, México. Maestro en Administración Industrial de Negocios, Doctorando en Relaciones Internacionales, Negocios y Diplomacia. Correo electrónico: juanagramon@gmail.com

2 Facultad de Ciencias Políticas y Relaciones Internacionales, Universidad Autónoma de Nuevo León, México. Magíster en Administración de Organizaciones, Doctorando en Relaciones Internacionales, Negocios y Diplomacia. Correo electrónico: jorge.lechugacrd@uanl.edu.mx

3 Facultad de Ciencias Políticas y Relaciones Internacionales, Universidad Autónoma de Nuevo León, México. Maestría en Calidad, Doctorando en Relaciones Internacionales, Negocios y Diplomacia. Correo electrónico: maria.arjonagrn@uanl.edu.mx 
States affecting the dynamics of inter-American international relations. It concludes that despite the agreement in 2014 between Washington and Havana, the Trump's government kept several acts of hostility that negatively affect this agreement; therefore, cooperation opportunities should be sought to improve bilateral relations.

Keywords: economic opening, Cuba, diplomacy, United States, international cooperation, inter-state relations.

\section{Introducción}

El artículo analiza la situación de Cuba con Estados Unidos en el ámbito de las relaciones internacionales y demuestra algunos aspectos de la apertura de nexos diplomáticos y comerciales, lo anterior con el propósito de brindar información sobre la conveniencia en términos de comercio, diplomáticos, comercial, culturales y sociales, que conlleva una posible normalización en las relaciones económicas entre estos dos países.

Las implicaciones de la política del presidente Trump revisten en importancia para el pueblo cubano, tanto por su histórica y complicada relación con Estados Unidos, como por el momento alcanzado después de los acuerdos entre los gobiernos Obama y Castro en 2014 (Mazzina y González, 2016); período en el que esta isla del Caribe evolucionaba en su modelo económico y una transición de poder generacional desde la revolución. En este sentido, el actual gobierno cubano se conduce con una mirada hacia las relaciones con la administración Trump y lo que ello pueda implicar (Alzugaray, 2017), tanto para el país como para la geopolítica interamericana.

El paso del tiempo no ha alterado las relaciones Cuba-Estados Unidos, marcadas por una ruptura en 1961 y una serie de actos de hostilidad liderados por Washington. En este orden de ideas, este estudio cobra importancia en la medida que analiza áreas de cooperación y conflicto y se realizan reflexiones a partir de ellas (Alzugaray, 2012).

La apertura diplomática de Cuba-Estados Unidos relajó las disposiciones causadas por el embargo que el gobierno estadounidense impuso a este país caribeño. Lo cual afectó positivamente a la isla en diversas áreas como la economía, el turismo, los negocios, la política y la cultura. La globalización ha permitido que Estados Unidos, a través de diversos conductos como las empresas multinacionales, los medios de comunicación, los inversionistas, entre otros, haya influido en la política interna cubana (Lechuga y Leyva, 2019). Así, las condiciones descritas anteriormente modificaron las formas de gobernar de antaño que imperaban en dicho territorio, mismas que afectaban diversos aspectos como la migración, los negocios locales, la libertad de expresión, entre otros (Canales, Fuentes y De León, 2019). 
La diferencia en el avance de las negociaciones entre ambos países depende en gran medida de los mapas electorales en Estados Unidos. La repercusión de la administración norteamericana (Trump) con relación a Cuba actualmente contempla considerar una afectación en los sectores de turismo e inversión extranjera directa derivada de la aplicación del Título III de la Ley Helms-Burton (Rodríguez y Pichs, 2019).

De esta forma, con el propósito de analizar este proceso de apertura, la primera sección del artículo incluye los antecedentes diplomáticos y comerciales entre Cuba y Estados Unidos, así como sus repercusiones correspondientes. La segunda, muestra la situación interna de ese país en diversos rubros sociales y económicos; mientras que la sección de conclusiones se esbozan los hallazgos con los elementos más relevantes del análisis del texto.

\section{Metodología}

El artículo se elabora desde un enfoque y metodología cualitativa, alcanzando un nivel analítico y diseño no experimental. De acuerdo con Hernández et al. (2014), este tipo de investigación "Utiliza la recolección y análisis de los datos para afinar las preguntas de investigación o revelar nuevas interrogantes en el proceso de interpretación" (p. 7). Por otro lado, Hernández et al. (2014), definen la investigación no experimental como la "Que se realiza sin la manipulación deliberada de variables y en los que sólo se observan los fenómenos en su ambiente natural para después analizarlos" (p. 149).

El artículo presenta un alcance interpretativo que pretende encontrar pautas de relación internas en un evento para llegar a un conocimiento más profundo de este, más allá de la mera descripción de los hechos. De esta manera, para la construcción del marco teórico-conceptual sobre las repercusiones de la apertura económica de Cuba con Estados Unidos, se consultaron un total de treinta y cinco (35) referencias bibliográficas, utilizándose como objeto de análisis las ideas, los argumentos y los proyectos que fueron interpretados desde una perspectiva crítico-analítica. Con relación a la comprensión del problema de la investigación, se recopilaron fuentes secundarias que comprenden documentos académicos. En el marco de referencia se definieron los conceptos básicos relativos a las repercusiones de la apertura económica de Cuba con Estados Unidos, se seleccionó y analizó la información para, finalmente, realizar la discusión y las respectivas conclusiones respecto a este proceso (Agramón y Lechuga, 2019). 


\section{Fundamentos conceptuales}

\subsection{Antecedentes diplomáticos entre Cuba y Estados Unidos}

Durante más de 50 años, Cuba fue un lugar rezagado y alejado del resto del mundo en el ámbito social, turístico y comercial; esto repercutió en que algunos productos y servicios como los automóviles, Internet y la infraestructura de las ciudades se hayan visto de alguna manera rezagada industrialmente, en comparación con los países desarrollados y en proceso de ello. Lo anterior fue una consecuencia del poco intercambio y apertura comercial que la isla había tenido con los otros Estados (Ibarra y Máttar, 1998). Además, los viajes y las transacciones financieras de los ciudadanos de EE. UU. a ese país fueron prohibidos. Acto seguido ocurrió la crisis de los misiles, la cual involucraba la presencia de la Unión Soviética en Cuba, que representó una amenaza hacia los Estados Unidos en el contexto de la Guerra Fría entre las dos potencias (Camargo et al., 2016).

Cuba se alió con la Unión Soviética, por lo cual Estados Unidos le impuso un embargo, considerándolo un país enemigo, en calidad de terrorista. Washington, además, aplicó medidas extremas en el ámbito de negociaciones, viajes, intercambios culturales, lo cual restringió el flujo libre de personas y del comercio entre los dos Estados. Por tales razones, Estados Unidos, no había establecido relaciones diplomáticas formales con este país caribeño, aunado al hecho de que Fidel Castro mantuvo la postura de oposición.

El embargo económico comprendía, entre otras situaciones, la imposición de sanciones que se podían aplicar a las compañías estadounidenses y no estadounidenses que negociaran con la isla. Por lo que cualquier persona física o jurídica que estuviera inmiscuida con tal país, ya sea mediante algún bien, financiamiento, propiedad, documento, entre otras disposiciones, estaría sujeta a decomiso por parte de Estados Unidos (Congress of the United States of America, 1996).

Lo anterior, significó para Cuba una reducción considerable en los negocios y en la apertura comercial con la mayoría de los países alrededor del mundo. Inclusive, al año 2019, los viajes a esta isla no estaban autorizados, a excepción de estar bajo algunas licencias y procedimientos que han de ser analizados por el consulado norteamericano de Estados Unidos (Embajada de los Estados Unidos, 2019). Como menciona Pérez (2011), las relaciones establecidas entre ambas naciones se basan en la historia de "una gran potencia y de un vecino débil, con gran sentido de sí mismo" (p. 62). 


\subsection{La democracia como vía de diplomacia entre estados}

Cuba cuenta con un reducido puntaje de participación ciudadana, lo cual se traduce en un nivel muy bajo de democracia y del estado de derecho; mientras que en cuanto a la imposición ejercida por parte del Estado, esta es de las más altas en relación a otros países (Bye, 2013). El punto anterior, contrasta con la ideología de Estados Unidos, que busca introducir la democracia a la isla y cambiar las formas socialistas y comunistas en dicho país, situación que constituye una amenaza para el gobierno cubano, ya que este impone condiciones a los negocios y a los comercios notablemente y tal cambio resultaría en una evidente reducción de fuerza del Estado.

La administración Obama combatió la resistencia del socialismo exhibido por Cuba, mediante una diplomacia incrustada en el nivel de la gente, expandiendo los contactos culturales, académicos y familiares. Dicha acción se hizo con el objetivo de promover la democracia en la isla, lo cual pavimentó el camino para que se llevara a cabo la primera elección de manera democrática en tal región (Gómez, 2018). La promoción de la democracia ha sido una constante diferencia entre las formas de gobierno de Estados Unidos y Cuba. Sin embargo, la búsqueda de ella fue una alternativa para aligerar las relaciones diplomáticas entre estos países. Pero, en los últimos años se dio lugar a un retroceso en las relaciones diplomáticas y económicas entre ambos Estados con la llegada de la administración Trump.

Es importante mencionar aquí que la democracia no necesariamente ha sido una vía de crecimiento para un Estado, ejemplo de ello son China y Vietnam, países cuya forma de gobierno se caracteriza por establecer imposiciones fuertes a su población para controlar una gran gama de condiciones. Lo cual les resultó una prosperidad muy por encima a la de Cuba, donde esta última sostiene un régimen similar al de los Estados mencionados, pero con la gran diferencia de que fue privada por un largo periodo de establecer relaciones económicas y diplomáticas con la mayoría de los países del mundo; lo cual resultó en un rezago notable en materia financiera, social, cultural, etc.

\section{Apertura de relaciones diplomáticas entre Cuba y Estados Unidos}

Después de que Estados Unidos y Cuba rompieran relaciones diplomáticas en 1961, finalmente, en 2014, Obama las reconstruyó a partir de una política exterior de Estado-Estado y mediante una diplomacia de "gente a gente". Esta forma tomó mayor relevancia con la promoción de la democracia a través de 
una estrategia de "poder blando" de Washington a La Habana; estrategia que, posteriormente, tendría repercusiones en la política interna de la isla.

Obama aligeró las restricciones con Cuba, permitió los viajes familiares y reanudó los envíos de remesas, el cual, después de los ingresos por venta de servicios profesionales al extranjero, conforma la mayor fuente de divisas de este país seguidos por el turismo. Las remesas aumentaron consistentemente en $143 \%$, de US $\$ 1,447$ millones en 2008 a US\$3,515 millones en 2017; inclusive ante las políticas de Trump, estas no las han tocado, por lo que su expansión continúa (Mesa, 2018). Durante el periodo de Obama, el cambio de relación diplomática entre esos países abrió actividades económicas, culturales, académicas, de intercambios de servicios y demás acciones; de manera que el comercio cubano logró mayor apertura con otros socios comerciales.

\subsection{Reversa de Donald Trump en las relaciones diplomáti- cas Cuba-Estados Unidos}

En solo meses, Obama relajó restricciones y tensiones de décadas de antigüedad entre ambos países, sin embargo, esto cambió con la llegada de Trump al poder, debido a ciertas tensiones y dudosos hechos sucedidos en la isla. Una de las razones, fue que dos docenas de diplomáticos estadounidenses comenzaron a informar dolencias misteriosas a fines de 2016 en La Habana. Por lo cual, la administración de Trump responsabilizó al gobierno de Cuba; retirando a la mayoría del personal diplomático residente en esta capital, además de expulsar un número igual de enviados cubanos de Washington. Adicionalmente, personal de la Embajada estadounidense en La Habana, no procesaría visas para los cubanos que busquen viajar a ese país.

Lo anterior, produjo lo que se calificó como un "cambio de ánimo" en la interacción Cuba-EUA, pudiendo tener efectos contraproducentes a los intereses de Estados Unidos (Domínguez, 2017). Por otra parte, se registró una disminución notable de visitantes canadienses y europeos, como consecuencia de la caída en calidad de los servicios hoteleros en Cuba. Por ejemplo, en el Hotel Playa Pesquero, 12 turistas contrajeron gastroenteritis en 2014, 29 en 2015, 34 en 2016, 41 en 2017 y 37 en 2018; lo cual resultó en una falta de confianza para los extranjeros hacia la isla (Mesa, 2018).

Como consecuencia de estas situaciones, Trump anunció la cancelación del acuerdo de Obama con Cuba y criticó los abusos contra los derechos humanos de ese gobierno, que consisten en el acoso persistente a los disidentes. Así, Washington elevó restricciones como una medida de freno al flujo de dinero 
para hacer frente a la "opresión comunista", ya que el ejército cubano está profundamente entrelazado con la economía, especialmente en la industria del turismo, donde numerosos hoteles y restaurantes les pertenecen. Por lo cual, Estados Unidos no cambió sus políticas sobre las condiciones para el turismo con Cuba (Badella, 2015). Asimismo, Trump amplió la lista de empresas cubanas manejadas por las Fuerzas Armadas que están prohibidas para los turistas estadounidenses; también, las compañías norteamericanas que operaban en la isla fueron limitadas a cualquier trato con aproximadamente 180 empresas vinculadas o controladas por el ejército cubano, ya que se visualiza al comercio como medio de propagación del socialismo.

Ahora bien, en territorio estadounidense, las restricciones comerciales de Trump afectaron en gran medida a las pequeñas empresas cubanas, como salones de belleza, restaurantes, lavados de autos y renta de residencias, lo que originó que, en 2017, el número de nuevos solicitantes de licencias de negocios privados se desplomara. Lo anterior, como consecuencia de la incertidumbre de los emprendedores, en relación con las restricciones que pudiesen surgir en tiempos posteriores (Wilkinson, 2018).

Se ha visto que el sector empresarial y financiero europeo ha sido afectado con sanciones, sin soporte en las leyes europeas o cubanas y que violan las normas básicas del derecho internacional. Mediante el lema de la Doctrina Monroe de 1823, Trump pretendía socavar el sistema político en la isla, además de minar la presencia europea allí (Pellón, 2019). Su política perseguía paralizar los intercambios académicos, educativos, culturales, es decir, cerrar el diálogo político de Cuba con el exterior. Dicha estrategia trata de remover el actual régimen imponiendo sanciones secundarias contra los países que no se integren a las directrices de Washington (López-Levy, 2019).

\section{Situación económica de Cuba en el ámbito de relaciones internacionales}

Los problemas recientes que han acechado a la isla son diversos, por mencionar algunos: la sequía seguida del huracán Irma, que produjo daños equivalentes al $9 \%$ del PIB; las medidas negativas de Trump contra el turismo; el descenso en la producción de crudo y gas; la continua reducción del suministro de petróleo, comercio y compra de servicios profesionales cubanos por parte de Venezuela. Este último punto causó una merma en el suministro petrolero interno y externo, que obligó a comprar US \$100 millones en el exterior, lo cual fue insuficiente para cubrir el déficit. Otros problemas son, el declive en los 
precios mundiales del azúcar y el níquel, el aumento del precio mundial de los hidrocarburos, entre otros.

Cabe destacar aquí el caso de Venezuela, país que importa más servicios médicos y académicos de Cuba, hasta un $75 \%$ de ellos. No obstante, su economía se ha deteriorado, con una inflación de un millón por ciento, aunado a una severa escasez de alimentos y medicamentos. Esto disminuyó la compra de servicios profesionales (la mayor fuente de divisas de $\mathrm{Cuba}$ ), el suministro de petróleo y el intercambio comercial (Mesa, 2018). La relación entre estos países se tornó negativa en términos comerciales, sugiriendo la necesidad de diversificar mercados por parte de la isla con el propósito de mejorar el flujo de divisas.

\subsection{Relación económica comparativa entre Cuba-Estados Unidos}

La tabla 1 muestra atributos económicos entre Cuba y Estados Unidos, con la intención de sacar a relucir las fortalezas y las debilidades de ambos, así como reflexionar sobre el posible campo de cooperación entre las partes si así fuese conveniente.

Tabla 1

Cuadro comparativo económico Cuba-Estados Unidos

\begin{tabular}{|c|c|}
\hline Cuba & Estados Unidos \\
\hline $\begin{array}{l}\text { Economía } 138 \text { en el mundo en relación } \\
\text { con las exportaciones. }\end{array}$ & $\begin{array}{l}\text { Tercera economía de exportación más } \\
\text { grande del mundo. }\end{array}$ \\
\hline $\begin{array}{l}\text { En el } 2017 \text {, exportó } 1.41 \text { billones } \\
\text { de dólares e importó } 6.21 \text { billones, } \\
\text { resultando en un balance negativo. }\end{array}$ & $\begin{array}{l}\text { Estados Unidos exportó } \$ 1.25 \\
\text { trillones de dólares e importó } \$ 2.16 \\
\text { trillones, lo que resultó en una balanza } \\
\text { comercial negativa de } \$ 910 \mathrm{~B} \text {. }\end{array}$ \\
\hline Principales exportaciones de Cuba: & Principales exportaciones de los \\
\hline azúcar cruda ( $\$ 514$ millones), tabaco & Estados Unidos: petróleo refinado (\$ \\
\hline enrollado (\$ 264 millones), níquel & 74.5B), automóviles (\$ 56B), aviones, \\
\hline mate (\$ 140 millones), licor fuerte ( $\$$ & helicópteros y / o naves espaciales \\
\hline $\begin{array}{l}109 \text { millones) y crustáceos ( } \$ 78,1 \\
\text { millones). }\end{array}$ & $\begin{array}{l}(\$ 54 \mathrm{~B}) \text {, turbinas de gas }(\$ 31.6 \mathrm{~B}) \text { y } \\
\text { medicamentos envasados }(\$ 29.5 \mathrm{~B}) \text {. }\end{array}$ \\
\hline En 2017, su PIB fue de $\$ 96.9 \mathrm{~B}$ y su & En 2017, su PIB fue de $\$ 19.4 \mathrm{~T}$ y su \\
\hline PIB per cápita fue de $\$ 8.43 \mathrm{k}$. & PIB per cápita fue de $\$ 59.5 \mathrm{k}$. \\
\hline
\end{tabular}




\begin{tabular}{|c|c|}
\hline Cuba & Estados Unidos \\
\hline $\begin{array}{l}\text { Principales importaciones: carne } \\
\text { de aves de corral (\$ } 246 \text { millones), } \\
\text { petróleo refinado ( } \$ 243 \text { millones), } \\
\text { petróleo crudo ( } \$ 208 \text { millones), trigo } \\
\text { (\$176 millones) y leche concentrada (\$ } \\
164 \text { millones). }\end{array}$ & $\begin{array}{l}\text { Principales importaciones: } \\
\text { automóviles (\$ } 178 \text { mil millones), } \\
\text { petróleo crudo (\$ } 129 \text { mil millones), } \\
\text { equipos de radiodifusión ( } \$ 105 \mathrm{mil} \\
\text { millones), computadoras ( } \$ 73.5 \mathrm{mil} \\
\text { millones) y piezas de vehículos (\$ } 67.1 \\
\text { mil millones). }\end{array}$ \\
\hline Principales destinos de exportación: & Principales destinos de exportación: \\
\hline China (\$ 379M), España (\$ 184M), & México (\$181B), Canadá (\$149B), \\
\hline Alemania (\$ 82.3M), Indonesia (\$ & China (\$133B), Japón (\$66.9B) y \\
\hline $55.4 \mathrm{M})$ y Singapur $(\$ 52.4 \mathrm{M})$ & Alemania (\$61.6B). \\
\hline Principales orígenes de importación: & Principales orígenes de importación: \\
\hline China (\$ 1.35B), España (\$ 1.01B), & China (\$476B), México (\$307B), \\
\hline México $(\$ 356 \mathrm{M})$, Argelia $(\$ 353 \mathrm{M})$ y & Canadá(\$274B), Japón (\$125B) y \\
\hline Brasil (\$ 345M). & Alemania (\$111B). \\
\hline
\end{tabular}

La información en la tabla ratifica que Estados Unidos, por ser una de las principales economías del mundo, cuenta con gran poder económico a pesar de su déficit comercial considerable, sin embargo, representa una enorme oportunidad para hacer negocios, debido a su capacidad de capital. Por mencionar algún aspecto con el propósito de dimensionar, el PIB per cápita estadounidense, es siete veces mayor que el de Cuba.

Los principales bienes que Cuba exporta son materias primas, mientras que en Estados Unidos son recursos transformados y más redituables económicamente. Los destinos primordiales de las exportaciones de Cuba lo conforman Estados considerablemente distantes (ver figura 1), en comparación a los de los Estados Unidos (México y Canadá), además, dichos vecinos geográficos, sí cuentan con comercio notable. No obstante, China es una piedra angular para ambos países en relación con las exportaciones e importaciones, debido a su notable crecimiento económico a nivel mundial. 
Figura 1

Saldo comercial Cuba- Socios Comerciales del mundo

\section{0,0}

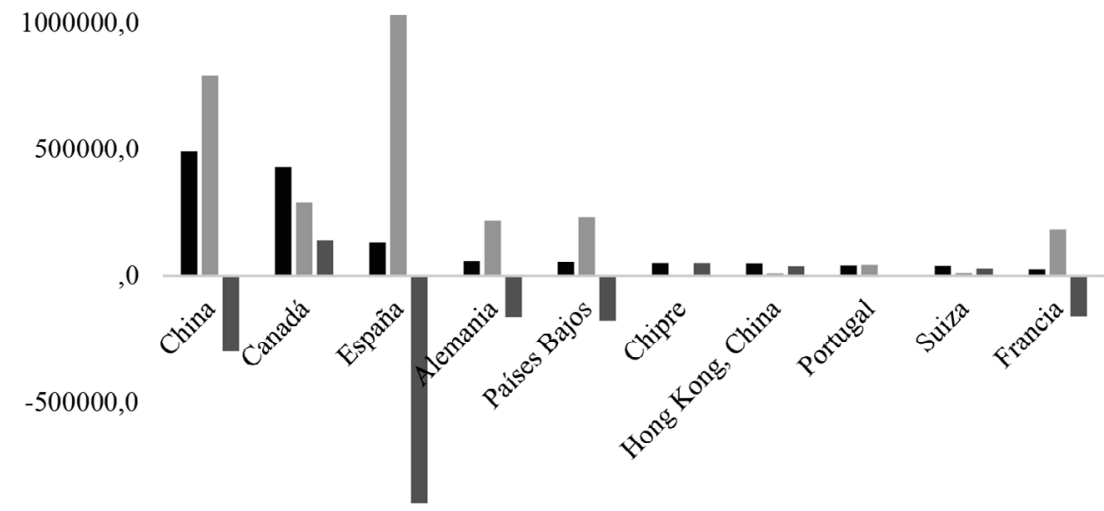

$-1000000,0$

$$
\text { - Exportaciones Importaciones } \quad \text { Saldo Comercial }
$$

Fuente: elaboración propia (2020). Datos: Trademap, en miles de dólares americanos.

Por otra parte, Estados Unidos, no aparece como importador de Cuba, por lo que se debe considerar la conveniencia de abrirse al mercado libre con este país norteamericano. Además, las exportaciones de alimentos y productos agrícolas estadounidenses a Cuba aumentaron más de un $25 \%$ en el año 2018, en comparación con 2017 (Wilkinson, 2018). Eso indica que, en relación con las exportaciones, efectivamente, Estados Unidos introduce bienes hacia la isla, mientras que, del otro lado, no parece haber alguna paridad en tal sentido.

\subsection{Turismo entre Cuba y Estados Unidos}

El turismo internacional representa la tercera fuente de divisas de Cuba, después de los servicios profesionales y el envío de remesas. Un aceleramiento en el turismo tomó lugar desde 2015, motivado por la normalización de relaciones entre Cuba y Estados Unidos a fines de 2014, bajo la presidencia de Obama, la cual facilitó los vuelos aéreos y viajes. Por otra parte, en el primer semestre de 2018 (comparado con el de 2017), los turistas estadounidenses disminuyeron en un $23.5 \%$, (-50\% por vía aérea, en contraste con el aumento de $115 \%$ por ruta marítima), donde los visitantes aéreos gastan un promedio de US \$766 
comparado con US $\$ 50$ que gastan los que llegan vía cruceros, por lo cual se estima que Cuba perdió US \$297 millones por dicha causa (Mesa, 2018).

Para el 2019, con un plan original de 5,1 millones de visitantes, se alcanzó un aumento del 5.8\% hasta mayo de ese año, con lo que se cumple el $90.6 \%$ de la proyección de ingresos. Contrariamente, el gobierno norteamericano integró medidas restrictivas que generan una disminución en un $20.3 \%$ en junio de 2019 , en relación al mismo período del año anterior, provocando que el pronóstico se plasmara en un 75\%. Es decir, en 2019 llegaron 4.3 millones de turistas, con un decrecimiento del $10 \%$ y un cumplimiento del $84.3 \%$, afectando el ingreso turístico, que se había previsto que creciera $17.6 \%$ en ese lapso (Rodríguez y Pichs, 2019).

El flujo de personas de Cuba hacia Estados Unidos ha sido una constante; las estimaciones datan de que un millón trecientos mil individuos nacidos allí emigraron, entre 1959 y 2004, hacia el país del norte. Lo cual invita a pensar que la isla no ofrece oportunidades óptimas a sus habitantes para desarrollarse de manera idónea y buscar mejores condiciones. Inclusive, dichos migrantes tienen que pasar por países como Ecuador, Nicaragua, México, entre otros, para llegar a su destino (Clot y Martínez, 2018). Razón por la que mantener relaciones diplomáticas favorables entre ambos Estados facilitaría el movimiento regular y seguro de personas, el empleo, el envío de remesas, la prestación de servicios, etc.

\subsection{Cuba en el contexto de la globalización: Medios de comunicación, ciencia y tecnología}

Durante los primeros años del siglo XXI, Cuba estableció relaciones con países de Sudamérica como los pertenecientes a la alianza ALBA, además de otras negociaciones con socios como Brasil y Argentina (Cazallo et al., 2019). En este contexto de acercamientos con diferentes Estados, el bloqueo comercial de Estados Unidos ha persistido y representa un gran obstáculo, no solo en el proceso de apertura y crecimiento económico de la isla, sino en explorar posibilidades para un proceso de democratización.

En ese proceso de apertura y, en el contexto de la globalización, hay una serie de actores y elementos que inciden también en la transformación de las sociedades, tales como las empresas, especialmente las empresas multinacionales, pero también la influencia de los medios de comunicación en la propagación de ideas y el desarrollo de la Ciencia y la Tecnología en el marco de la economía del conocimiento. 
Respecto a las tecnologías de información, estas trasladan rasgos sociales y costumbres de una población a otra, en territorios distantes y con diferentes valores; además, repercuten en cambios de pensar de la ciudadanía, debido a la influencia o ideologías provenientes de otros lugares, las cuáles aceleran la posibilidad del surgimiento de revoluciones sociales en dichos Estados (Schiavon et. al., 2014).

La difusión es un efecto de propagación o contagio, es decir, la forma en que se "transportan" elementos o fenómenos de un lugar a otro, por lo que, en un mundo civilizado e interconectado, los medios de comunicación y las redes sociales facilitan la difusión de ideas, noticias y demás mensajes entre las comunidades de distintos países, sin importar sus límites geográficos (Schiavon et al., 2014). En el caso de Cuba, el contacto cercano con los emigrantes y recursos como el Internet son elementos que impactan en la interacción cada vez mayor de este país con el resto del mundo (Torres, 2017). Así, en función de preservar los valores, creencias, costumbres y demás cuestiones propias del Estado, gobiernos de naturaleza autoritaria como los de Cuba y China, por ejemplo, restringen el acceso a este recurso tecnológico.

El gobierno de Cuba empleó una restricción excesiva sobre la diseminación de tecnologías de información y de intercambio cultural, de manera que los habitantes tenían prohibido abandonar el país. Las fuertes limitaciones de Internet en Cuba representan un freno efectivo a la proliferación de redes sociales, razón por la cual, los medios de comunicación formaron parte fundamental, dentro de las estrategias de Obama, para introducir la democracia como una influencia de oposición en la población hacia la postura socialista del gobierno cubano (Badella, 2015).

Una de las pocas arenas donde los jóvenes pueden expresar e intercambiar frustraciones y protestar públicamente es a través de la música, dónde varias subculturas como el hip hop, rap, reggaetón tienen una fuerte influencia en ellos para cuestionar enérgicamente a los dirigentes cubanos. Esta ha sido propagada históricamente de manera ilegal, ya que no puede ser emitida libremente en las estaciones de radio, lo cual plantea las dudas sobre si pudiese existir un levantamiento de multitudes en contra del régimen a este nivel.

Respecto a la música, los socialistas afirman que esta es "un ensayo de política" o "una forma de política en sí misma"; "Un recordatorio doloroso [...] de la brecha creciente entre los valores emergentes enraizados en la experiencia de la vida cotidiana y la ideología socialista" (Bye, 2013), ejemplo de ello fue la llegada de los Rolling Stones a Cuba, justo días después de la primera visita de Obama a dicho país. No obstante, durante el concierto, las comunicaciones por Internet se 
restringieron; en este punto es importante mencionar que la música de la banda ha sido prohibida en dicho territorio por más de 50 años (Robles, 2016).

La música y los medios de comunicación representan un canal donde la diplomacia entre Estados se abre. El manejo de las emociones colectivas incide a través de las redes sociales (Van Wyk, 2017). Asimismo, estas son vías de libre expresión y de pensamiento para las personas en la búsqueda de una política abierta, que dé lugar a una participación más activa y receptiva hacia la democracia. Por su parte, las redes sociales y el Internet pueden causar que sociedades de Estados distantes lleguen a ser influenciadas en sus normas y políticas, ya que estas actúan como un efecto de propagación o contacto de manera prácticamente instantánea, provocando así, mayores canales de comunicación que generan acciones con impactos múltiples en diversos territorios.

Lo anterior, hace hincapié en el hecho de que la difusión transnacional brinda la posibilidad latente de influir en las políticas de los países alrededor del mundo (Schiavon et al., 2014) y la posibilidad para los Estados de intervenir en la mente de su población por medio de las diversas tecnologías de información, las cuales pueden emplearse como una estrategia de convencimiento para fines particulares.

Otras áreas de gran transcendencia en los procesos de globalización son la ciencia y la tecnología, que constituyen una piedra angular para que los Estados se desarrollen y sean competitivos, razón por la cual deben estar a la vanguardia en dicho ámbito para no verse aventajados por sus semejantes (Acuña, 1993). Estas disciplinas han sido ampliamente fomentadas en la isla, dando como resultado 221 centros de investigación y desarrollo, con alrededor de 21 mil docentes, de los cuales 5 mil se dedican a la investigación científica. Esto ratifica que Cuba cuenta con un capital humano sólido y con una tasa de empleo de más del $1 \%$ del PIB cubano. Para muestra de esto, en 2019, el Centro de Histoterapia Placentaria descubrió un método para la cura del Vitíligo que afecta a miles de personas en el mundo, hecho por el que Cuba recibió el reconocimiento de la ciencia médica (Martínez, 2019). Lo anterior es solo un ejemplo del potencial de la isla en estas áreas, mismas que pueden ser utilizadas como moneda de cambio para competir internacionalmente.

\section{Discusión}

La adopción de alternativas comerciales más abiertas y democráticas en el territorio cubano podría redituar en un flujo más libre de la democracia y la cultura estadounidense en la isla, con posibilidades de incidir en afectaciones al control 
preponderante por parte del Gobierno y de la fuerza militar en muchos negocios, así como en la política, la ideología y demás ámbitos de la sociedad. No obstante, ese acercamiento a regímenes más democráticos, como lo es Estados Unidos, podría representar obstáculos para negociar con China y Rusia.

Es importante mencionar aquí que China es el principal adversario comercial de Estados Unidos y perfila convertirse en la primera economía mundial en 2030 (Allison, 2017). Ese país oriental y Rusia buscan capitalizar el tambaleo de las relaciones diplomáticas cubano-estadounidenses, con el fin de establecer una alianza para continuar la guerra comercial entre el gigante asiático y el país norteamericano. La posibilidad de una Cuba más cercana a China y Rusia significaría un retroceso diplomático notable con su vecino y clásico rival: Estados Unidos. Lo anterior, especialmente en el contexto de la configuración de las relaciones bilaterales auspiciada por Trump, mismo que abrió la puerta para que Beijing y Moscú busquen capitalizar dicha oportunidad en la isla, financiando infraestructura y otros proyectos de desarrollo cubanos; situación que, naturalmente, genera alarmas para el país del norte (Wilkinson, 2018).

Por su parte, la división entre la población emigrante cubana en EE. UU. que apoya a Trump (cerca del 50 \%) enfatiza la separación entre la nación a ambos lados del estrecho de Florida (López-Levy, 2019). La estrategia del Departamento de Estado consiste en alejar inversionistas tanto de otros países como los cubano-estadounidenses interesados en edificar la comunidad emigrada. En adición a lo anterior, se presenta una negativa de visas y castigos para inversionistas europeos en la isla y sus parientes, esto a favor de los intereses norteamericanos con un enfoque a largo plazo y a escala global (López-Levy, 2019).

De esta manera, los desafíos por considerar para Cuba corresponden a una mayor complejidad en el avance de las reformas, el endurecimiento de la política de Trump con la afectación en atraer inversiones a la isla, esto tomando en cuenta la dificultad económica que enfrentó en el año 2016 (Rodríguez, 2017; Triana, 2017), resultado del impacto de la crisis venezolana y la reducción de envíos de petróleo desde este país. Es en este contexto que también surge la incógnita sobre la continuidad y profundidad de los cambios que ha experimentado adentro la isla. En el tanto se requiere, entre otras cosas, gestionar internamente hacia las siguientes generaciones la transición de la dirigencia, con objeto de crear la legitimidad y la sustentabilidad de lo ya logrado con miras a un nuevo modelo social (Serbin, 2017). 


\section{Conclusiones}

Se considera que, sobre la base de los resultados obtenidos con la realización de la revisión documental, es posible identificar las siguientes conclusiones generales:

El análisis del proceso de apertura de Cuba hacia los Estados Unidos ha de tomar en consideración los factores positivos y negativos abordados en este artículo, así como una estrategia para afrontar futuras situaciones en un marco global, ya que la competitividad de los Estados en la actualidad está en gran parte dominada por mecanismos, entidades y actores nuevos como lo son las empresas multinacionales, las finanzas internacionales, las plataformas digitales y la economía del conocimiento.

El propiciar una apertura comercial más democrática con los Estados Unidos, abriría más mercados globalmente, redituando de manera positiva en el ámbito económico y político de la isla. De esta forma, se requiere implementar una estrategia competitiva que facilite un proceso interno de cambio, que edifique los cimientos para consolidar la visión de crecimiento con fundamento en las capacidades y recursos con que cuenta este país caribeño.

Finalmente, es posible afirmar que el presente estudio sirve como paso previo para futuras líneas de investigación que incluyan un análisis empírico encaminado a profundizar en el conocimiento de las relaciones comerciales entre Estados Unidos y Cuba, así como la investigación empírica de temáticas vinculadas con la influencia de los medios de comunicación (Internet, redes sociales, radio, televisión, etc.) como una ventana de apertura económica y cultural en países de corte socialista-comunista, facilitando insumo cualitativos, pero también de naturaleza cuantitativa y estadísticamente relevantes en la materia. 


\section{Referencias}

Acuña, P. (1993). Vinculación universidad-sector productivo. Revista de la Educación Superior, 22 (87), 1-15.

Agramón, J. y Lechuga, J. (2019). Las disposiciones de transferencia de tecnología hacia los investigadores en las principales instituciones de educación superior públicas de producción científica en México. Innovaciones de $\mathrm{Ne}$ gocios, 16(32), 304-331.

Allison, G. (2017). Destined For War. Can America and China Escape Thucydes's Trap?, Estados Unidos: Ediciones HMH.

Alzugaray, C. (2017). La política exterior cubana de Cuba en la era Trump. Pensamiento Propio, 45, 205 -220.

Alzugaray, C. (2012). Las (inexistentes) relaciones Cuba-Estados Unidos en tiempos de cambio. Nueva Sociedad, 242, 139 - 148.

Badella, A. (2015). Obama and US Democracy Promotion in Cuba: New Strategies, Old Goals? Caribbean Journal of International Relations \& Diplomacy, 3 (2), 7-35.

Bye, V. (2013). The Politics of Cuban Transformation - what Space for Authoritarian Withdrawal? Norwegian Institute of International Affairs. https://www. nupi.no/en/Publications/CRIStin-Pub/The-Politics-of-Cuban-Transformation-what-Space-for-Authoritarian-Withdrawal

Camargo, J., Miranda, G. y Karlsson, H. (2016). Un hangar para misiles nucleares reutilizado como casa de vivienda, almacén y comedor. Cuba Arqueológica, 9 (1), 7-16.

Canales, A.; Fuentes, J. y De León Escribano, C. (2019). Desarrollo y migración: desafíos y oportunidades en los países del norte de Centroamérica (Comisión Económica para América Latina y el Caribe - CEPAL). https://repositorio.cepal.org/bitstream/handle/11362/44649/1/S1000454_es.pdf

Cazallo, A.; Meñaca, I.; Lechuga, J. y García, J. (2019). La Alianza del Pacífico y los Brics: dos modelos de competitividad país. Revista Lasallista de Investigación, 16 (2), 122-141. http://dx.doi.org/10.22507/rli.v16n2a11

Clot, J. y Martínez, G. (2018). La «odisea» de los migrantes cubanos en América: modalidades, rutas y etapas migratorias. Revista pueblos y fronteras digital, 13, 1-30. https://dx.doi.org/10.22201/cimsur.18704115e.2018.v13.345

Congress of the United States of America. (1996). Cuban Liberty and Democratic Solidarity (Libertad) Act of 1996. One Hundred Fourth Congress of the 
United States of America. https://web.archive.org/web/20070926035730/ http://www.treasury.gov/offices/enforcement/ofac/legal/statutes/libertad.pdf

Domínguez, J. I. (2017, 19 de junio). Trump quiere negociar con La Habana. ¿Le saldrá el tiro por la culata? The New York Times. https://www.nytimes.com/ es/2017/06/19/espanol/opinion/trump-quiere-negociar-con-la-habana-le-saldra-el-tiro-por-la-culata.html

Embajada de los Estados Unidos. (2019). Viajes a Cuba. https://cu.usembassy.gov/ es/u-s-citizen-services-es/local-resources-of-u-s-citizens-es/viajes-a-cuba/

Gómez, J. (2018). Cuba: elecciones y luego ¿qué?, CNN. https://cnnespanol.cnn. com/2018/03/28/cuba-elecciones-y-luego-que/

Hernández, R., Fernández, C., y Baptista, P. (2014). Metodología de la investigación, México: Mc Graw Hill.

Ibarra, D. y Máttar, J. (1998). La economía de Cuba. Revista CEPAL, 29-37. https:// www.cepal.org/es/publicaciones/12153-la-economia-cuba

Lechuga-Cardozo, J., y Leyva-Cordero, O. (2019). Escenarios 2020 del Orden Mundial. Análisis desde la Prospectiva Estratégica. ÁNFORA, 27(48), 137161. https://doi.org/10.30854/anf.v27.n48.2020.672

López-Levy, A. (2019). Cuba y el gobierno de Trump: retorno al conflicto e implicaciones para la relación triangular con Europa. Análisis Carolina, 8, 2-19.

Martínez, F. (2019). Médicos logran la cura para el vitíligo. Revista de divulgación científica y tecnológica de la Universidad Autónoma de Nuevo León. Ciencia, 20-85. http://cienciauanl.uanl.mx/?p=4112

Mazzina, C. y González, M. (2016). Las relaciones cubano-estadounidenses: las necesidades políticas detrás del acuerdo. Revista Relaciones Internacionales, 89(1), 37-60. http://dx.doi.org/10.15359/ri.89-1.2

Mesa, C. (2018). La economía cubana: situación en 2017-2018 y perspectivas para 2019. https://cubaposible.com/wp-content/uploads/2018/12/Informeecon $\%$ C3\%B3mico-Cuba-Posible-2017-2018-perspectivas-2019.pdf

Observatorio de Complejidad Económica (2017, a). Cuba. https://oec.world/en/ profile/country/cub

Observatorio de Complejidad Económica (2017, b). United States. https://oec.world/ en/profile/country/usa/

Pellón, Y. (2019). Relaciones Cuba- UE Balance y Perspectivas en un contexto interno bilateral e internacional cambiante. Ventana politica. http://www. ventanapolitica.cu/articulo/relaciones-cuba-ue-balance-y-perspectivas-enun-contexto-interno-bilateral-e-internacional) 
Pérez-Stable, M. (2011). The United States and Cuba: Intimate Enemies. Routledge.

Robles, F. (2016). Another First for Cuba: A Concert by the Rolling Stones. The New York Times. .https://www.nytimes.com/2016/03/27/arts/music/anotherfirst-for-cuba-a-concert-by-the-rolling-stones.html

Rodríguez, J. L. (2017). La economía cubana 2016-2017. Valoración preliminar (I). Cubadebate. http://www.cubadebate.cu/opinion/2017/01/01/ la-economia-cubana-2016-2017-valoracion-preliminar-i/

Rodríguez, J. y Pichs, R. (2019). Resumen sobre la evolución de la economía mundial primer semestre de 2019. Agosto de 2019. Centro de Investigaciones de la Economía Mundial (CIEM). http://biblioteca.clacso.edu.ar/Cuba/ ciem/20170628043911/pdf_1161.pdf

Schiavon, J; López, M., Velázquez, R. y Ortega, A. (2014). Teorías de Relaciones Internacionales en el Siglo XXI: Interpretaciones Críticas desde México (2nda. Ed.). BUAP; COLSAN; UABC; UANL; UPAEP.

Serbin, A. (2017). Cuba: legados del pasado y retos del presente. Pensamiento Propio, 45, 7- 31 .

Torres, R. (2017). El proceso de actualización del modelo económico y social de Cuba. Pensamiento Propio, 45, 7-31. http://www.cries.org/wp-content/ uploads/2017/09/006-Torres.pdf

Triana, J. (2017). ¿Por qué la economía no avanza? en Cartas de Cuba, 5 de enero de 2017.

Van Wyk, J. (2017). The politics of anger in an angry world .Mail \& Guardian. https:// mg.co.za/article/2017-06-02-00-the-politics-of-anger-in-an-angry-world/.

Wilkinson, T. (2018). A year after Trump reversed Obama's opening to Cuba, the U.S. is sitting out Havana's political revamp. Los Angeles Times. https:// www.latimes.com/nation/la-na-pol-us-cuba-20180622-story.html. 